\title{
Water Budget Approach to Quantify Corn Grain Yields Under Variable Rooting Depths
}

\author{
D. J. Timlin,* Y. Pachepsky, V. A. Snyder, and R. B. Bryant
}

\begin{abstract}
This study investigated the relationships between corn (Zea mays L.) grain yield and weather over a range of soil rooting depths with and without irrigation. The purpose was to test if variability of corn grain yield over a range of soil rooting depths could be reduced if water is supplied via irrigation. An additional goal was to test a simple water balance simulation model which calculates a seasonal moisture stress index based on relative evapotranspiration deficits. Such a water budget model could be used to estimate variations in corn grain yields as a function of spatial differences in soil depth and available water holding capacity in site specific agriculture. Corn grain yields were measured over a 3-yr period from 70 plots at the Cornell University Robert Musgrave Research Farm at Aurora, NY, USA. Soil depths ranged from 0.2 to $1 \mathrm{~m}$. During one year of the study, paired irrigated and non irrigated plots were placed at locations that had varying soil rooting depths. Irrigation resulted in significant increases in grain yield with the greatest response occurring on the soils with less than $0.5 \mathrm{~m}$ of rooting depth. Yields under irrigation were similar at all soil depths suggesting that, as soil depth decreased on these soils, water was the major limiting factor. The water budget model gave satisfactory estimates of grain yields as a function of soil depth and available water capacity and appears to be a useful tool to estimate corn grain yield as a function of soil depth and available water. The estimated potential yields can be used as a guide for site specific soil management given variations in available water holding capacity that affect potential soil productivity.
\end{abstract}

$\mathrm{M}$ UCH OF THE VARIABILITY of crop response is related to soil properties that affect water availability (Boyer et al., 1990). Effective soil rooting depth is one such property. Frye et al. (1983) reported higher correlations between corn grain yields and soil depths during years of low rainfall than years with greater rainfall where plant rooting depth was limited by a fragipan. Swan et al. (1987) observed that corn grain yield-soil depth relationships were significantly influenced by climate; during dry years the relationships were more pronounced. Gantzer and McCarty (1987) reported that topsoil depth (assumed to be A horizon material) was highly correlated to corn yield and the regressions were stronger in a dry year which indicated a contribution of water holding capacity. Changes in soil properties other than water holding capacity, however, also influence yields as topsoil depth decreases (Thompson et al.,

Dennis Timlin, USDA-ARS, Alternate Crops and Systems Lab., Bldg. 007, Rm. 116, BARC-West, 10300 Baltimore Ave., Beltsville, MD, 20705, and Yakov A. Pachepsky, USDA-ARS Hydrology and Remote Sensing Lab., Bldg. 007, Rm. 106, BARC-W, 10300 Baltimore Ave., Beltsville, MD 20705, Victor A. Snyder, College of Agricultural Sciences, P.O. Box 21360, Rio Piedras, PR 00928; and Ray B. Bryant, Dept. of Soil, Crop, and Atmospheric Sciences, Bradfield Hall, Cornell Univ., Ithaca, NY 14853. Received 17 Aug. 1999. *Corresponding author (dtimlin@asrr.arsusda.gov).

Published in Soil Sci. Soc. Am. J. 65:1219-1226 (2001).
1991). These properties include soil bulk density and chemical properties.

An objective of site specific management is to apply appropriate levels of agricultural inputs to localized areas. Since areas with deeper soils that facilitate extensive root growth tend to be more productive, it would be useful to have a tool to estimate or quantify the potential productivity due to water availability related to soil depth. An estimate of the spatial distribution of potential soil productivity can be obtained from knowledge of the spatial variability of soil depth. The relationship between soil properties and fertilizer requirements should be considered for site specific management (Cahn et al., 1994). Fertilizer or seed applications could therefore be tailored for the potential response of the crop as a function of soil depth and water availability (Mathews et al., 1997; Barnhisel et al., 1996).

Crop simulation models have become a useful tool to characterize and quantify yield and available water. Paz et al. (1998), using a soybean model, showed that yield variability correlated with variability of simulated water stress. Rooting depth and soil water holding capacity were important variables. Soil depth was an important parameter in a productivity index model used by Khakural et al. (1996) to estimate the spatial variability of crop yields. Moore and Tyndale-Brisco (1999) using crop models showed that much of the variability of wheat response to nitrogen could be explained by differing soil water holding capacities. Mathews and Crosser (1997) used CERES-wheat to study variable rate nitrogen application. They reported that the optimal nitrogen distribution was to apply more fertilizer to deeper soils and less to shallow soils.

Many of the models currently applied in precision agriculture have complex input requirements and may be more detailed than necessary for certain applications. They also require some form of calibration. Timlin et al. (1986) described a simple water budget model that calculated corn grain yields in shallow soils. The model was based on the assumption that a major portion of the yield variability in an otherwise uniformly managed field, is due to variability in soil available water. This in turn would be a function of depth to some root restricting layer, pore size distribution, and weather. The model only requires knowledge of soil water holding capacity, rooting depth, crop growth stages, and weather data.

The purpose of this study was to gain further understanding of yield and available water relationships under varying seasonal weather conditions and soil rooting depths. The objectives were (i) to determine if the effect of soil depth on yield is mainly due to reduced water availability and (ii) to evaluate the use a simple water budget to describe corn grain yield variability due to variation in soil depth. 


\section{MATERIALS AND METHODS Site Description}

The study site was at the Cornell University Robert Musgrave Research Farm at Aurora, NY. The dominant soils at the Aurora site are Lima loam (fine-loamy, mixed, mesic Glossoboric Hapludalf), and Aurora silty clay loam (fineloamy, mixed, mesic Glossaquic Hapludalf). The Lima loam and Aurora silty clay loam are both moderately well drained soils formed in calcareous glacial till. The Lima loam is deep to bedrock but has a root restricting layer of dense basal till at depths varying from 0.45 to $0.8 \mathrm{~m}$. The Aurora silty clay loam solum is underlain by calcareous siltstone at depths ranging between 0.5 and $1 \mathrm{~m}$ although some eroded areas have depths as shallow as $0.2 \mathrm{~m}$. The field chosen for the study includes a flat summit, shoulder slope, and backslope positions. The slope varies from 0 to $5 \%$ and the cross slope configuration is smooth.

Soil depth, defined as depth to bedrock, was measured with a hand auger. Soil water characteristics were measured at selected sites on cores or clods using a pressure plate apparatus. Water content at wilting point was taken to be that at $-1.5 \mathrm{MPa}$ using disturbed samples. The matric potential corresponding to field capacity was the tensiometer reading at $2 \mathrm{~d}$ after a saturating rainfall, when evapotranspiration was minimal.

The Aurora site had been in continuous corn. The field was moldboard plowed in the spring to $0.15 \mathrm{~m}$ and treated before planting with atrazine [6-chloro- $N$-ethyl- $N$ '-(1-methylethyl)-1,3,5-triazine-2,4-diamine] to control weeds. The field was fertilized with $30 \mathrm{~kg} \mathrm{ha}^{-1}$ nitrogen, $60 \mathrm{~kg} \mathrm{ha}^{-1}$ phosphorus, and $30 \mathrm{~kg} \mathrm{ha}{ }^{-1}$ potassium. An early season variety of corn was planted in $0.76-\mathrm{m}$ rows and nitrogen was sidedressed at the rate of $70 \mathrm{~kg} \mathrm{ha}^{-1} \mathrm{~N}$ as anhydrous ammonia.

Yields were recorded over three growing seasons. In 1983 and 1984, yields were harvested at the nodes of a grid; yields from a total of 70 plots were recorded. The grid cells measured 20 by $17 \mathrm{~m}$. Each plot was two rows wide by $5.3 \mathrm{~m}$ long and was located at the upper left hand corner of the grid cell, except in 1983 when four rows per plot were harvested. In 1985, the grid locations were not harvested due to weed problems. Instead, five transects parallel to the slope and containing 13 to 16 plots each were harvested to determine yield from areas where weeds had been controlled.

Nine pairs of irrigated and non irrigated plots were set out along transects. The irrigation experiment was carried out over one growing season, during the summer of 1985. Each plot included four corn rows $6.1 \mathrm{~m}$ long and the pairs of plots were separated by distances of approximately 10 to $20 \mathrm{~m}$. The irrigated and non irrigated plots were instrumented with tensiometers installed at $0.15 \mathrm{~m}$ depth intervals. Gypsum blocks were installed in the non irrigated plots to cover matric potential ranges more negative than about -80 to $-100 \mathrm{kPa}$. A pressure transducer as described by Marthaler et al. (1983) was used to measure the air pressure inside the partially water filled tensiometers. Irrigation was carried out when the soil water tension, as measured by the tensiometers in the 0 to $0.3-\mathrm{m}$ layer, reached $-50 \mathrm{kPa}$. Irrigation in each plot was accomplished by connecting four parallel drip irrigation lines to two 264-L barrels. Each drip irrigation line was no more than $15 \mathrm{~cm}$ from the crop row. The inner two rows of each four-row plot were harvested for yield determination.

Weather data were collected at Aurora from a weather station at the farm office located about $1 \mathrm{~km}$ from the field. The weather data include daily max-min temperatures, precipitation, and class A pan evaporation.

Sixteen years of meteorological, and corn grain yield and crop phenological data also were obtained from the crop- climate experiments at Canton Agricultural and Technical College at Canton, NY (R.F. Lucey, unpublished data, 1984). Recommended management practices and a short season hybrid of corn (Funk G-11-A) were used. Soil water holding capacities were also available. These data were used for further testing and validation of the model.

\section{Model Background}

Corn grain yield predictions in the Soil Depth-Soil Productivity Model (SD-SPM) are based on the relationship between relative yields and relative transpiration rates (Hanks, 1974):

$$
\frac{\text { Actual Yield }\left(Y_{a}\right)}{\text { Potential Yield }\left(Y_{p}\right)}=\frac{\text { Actual Transpiration } T_{a}}{\text { Potential Transpiration } T_{p}}
$$

Yields are estimated from a water budgeting procedure that calculates the relative transpiration ratio.

The SD-SPM requires weather, soil, and crop data. Weather data include daily evapotranspiration and rainfall throughout the growing season. Soil data required by the model are depth to a root restricting layer, soil water holding capacities, and the water content at wilting point of the soil horizons. As a first approximation, the $1.5 \mathrm{MPa}$ water content is used for the wilting point water content. Most of the water held in soil pores at tensions greater than $1.5 \mathrm{MPa}$ can be potentially lost through evaporation and is not readily available to field crops such as $Z$. mays. These soil data are generally available from standard soil characterization.

Plant data that the model requires include the maximum potential rooting depth, the depth at which the rooting density is one half that at the surface for a fully developed root system grown to the potential depth, and the distribution of corn growth stages. A 1-m depth was used as the maximum potential rooting depth for corn hybrids specific to the soils and climate of New York (Olson, 1983). Layers with a bulk density $>1.8 \mathrm{Mg} \mathrm{m}^{-3}$ were considered restricting to root growth (Olson, 1983). In non restricting subsoils, the depth at which the root length density is one half that of the surface can be taken to be one half the potential rooting depth (i.e., $0.5 \mathrm{~m}$ ) (Mengel and Barber, 1974). If there are soil horizons that have a bulk density $>1.50 \mathrm{Mg} \mathrm{m}^{-3}$ with few roots at some depth $<0.5 \mathrm{~m}$, then the depth of the lower boundary of this horizon can be used. The limiting value of $1.5 \mathrm{Mg} \mathrm{m}^{-3}$ was determined from an analysis of data from Fehrenbacher and Rust (1956). The depth at which root length density is one half the root density at the soil surface was estimated from soil characterization data and profile descriptions.

Crop growth stages are input to the model. Corn growth stages used in the model are vegetative, late vegetative, silking, blister kernel, and maturity (Table 1). If crop growth stages are not known, the calendar dates when the crop reaches late vegetative and silking stages can be estimated from cumulative heat units since planting. The number of heat units required for the corn crop to reach a given growth stage can be obtained by comparing accumulated heat units and measured crop phenological data over a period of several years (Daynard, 1972).

\section{Soil Water Budget}

The soil water budgeting procedure was adapted from the PLANTGRO model, which is fully described by Hanks (1974) and Retta and Hanks (1981). PLANTGRO has been adapted by changing the methods by which plant water uptake and root growth are modeled, and corn grain yields are calculated. In PLANTGRO, root density was not a factor in water uptake.

In SD-SPM, a root growth function adapted from Davidson et al. (1978) was used to calculate relative root density. The 
Table 1. Definition of growth stages and weighting factors used in the model.

\begin{tabular}{llc}
\hline Growth stage & \multicolumn{1}{c}{ Duration of growth stage } & $\begin{array}{c}\text { Weighting } \\
\text { factor }\end{array}$ \\
\hline $\begin{array}{l}\text { Vegetative } \\
\text { Late vegetative }\end{array}$ & $\begin{array}{c}\text { Emergence to 40 d after planting } \\
\text { From 40 d after planting to late } \\
(\mathbf{7 5 \% )} \text { tassel development }\end{array}$ & $\mathbf{0}$ \\
Silking and pollination \\
Blister kernel & $\begin{array}{l}\text { Late tassel until 75\% silking } \\
\text { Period lasting 15 d after 75\% } \\
\text { silking } \\
\text { Period from 15 d after 75\% silking } \\
\text { until harvest }\end{array}$ & $\mathbf{1}$ \\
\hline
\end{tabular}

root growth function was configured to calculate a root distribution that, at maturity, extends to a specified lower boundary and has one half the surface root density at a specified depth (both given as input). The purpose of this function was to obtain a reasonable relative root distribution with depth. The maximum potential corn rooting depth and the depth at which root length density is one half that at the surface for a mature root system are input parameters. The maximum potential rooting depth for a particular soil is defined as the maximum depth roots would reach in a deep well drained soil similar to that soil type. It is assumed that maximum potential rooting depth is reached at the time the crop has fully tasselled. Lateral root growth may continue until $75 \%$ of the crop has silked.

Calculated root density in the model is assumed to be independent of the presence of a root restricting layer below it. Where soil conditions restrict root growth, the potential root system is simply truncated at the depth of the restricting layer. While this may not be accurate, the purpose of the root growth routine is to only to provide an approximate measure of root distribution to model relative water uptake from different layers given simple and easily obtainable input data.

The root length density, $R\left[\mathrm{~cm}\right.$ root $\left.(\mathrm{cm} \text { depth })^{-1}\right]$, at any time, $t$, and depth, $z$, is defined as:

$$
R=R(t)_{M A X} \operatorname{Exp}\left[-\alpha Z^{2}\right] \cos \left[\frac{Z}{2 L(t)}\right]
$$

where $R(t)_{\text {MAX }}$ is the maximum root length density near the soil surface $(\mathrm{Z} \sim 0)$ at time $t, \alpha$ is a term that gives the root distribution function its shape $\left(\mathrm{cm}^{-2}\right), Z$ is depth, and $L(t)$ is the vertical extent of the roots at time $t$. Time, $t$, is defined as days after planting. The shape factor, $\alpha$, the depth of the roots, $L$, the maximum root length density near the surface, $R_{M A X}$, and the depth, $Z_{1 / 2}$, at which the root length density is one half $R_{M A X}$, at time $t$ are modeled as quadratic functions in time. $\alpha, R_{M A X}, L$, and $Z_{1 / 2}$, are:

$$
\begin{aligned}
\alpha & =\frac{\ln \left[2 \cos \left(\frac{Z_{1 / 2}}{2 L}\right)\right]}{Z_{1 / 2}^{2}} \\
R_{M A X} & = \begin{cases}0 & t \leq 5 \\
-0.5253 t^{2}+24.267 t-120 & t>5\end{cases} \\
L & = \begin{cases}0.06 t^{2}-0.1 t & t \leq 29 \\
\beta_{1} t^{2}+\beta_{2} t-\beta_{3} & t>29\end{cases} \\
Z_{1 / 2} & = \begin{cases}L \beta_{4} t^{2}+\beta_{5} t+\beta_{6} & \\
0.3 L & Z_{1 / 2}<0.3 L\end{cases}
\end{aligned}
$$

There are several fixed conditions: (i) the depth of the roots at $29 \mathrm{~d}(0.47 \mathrm{~m}$ here), (ii) the potential depth of the roots at the end of the tasseling stage (given as input), (iii) the depth at which root length density is one half that at the surface $\left(Z_{1 / 2}\right)$ at the time of $75 \%$ silking (given as input), (iv) $Z_{1 / 2}$ is

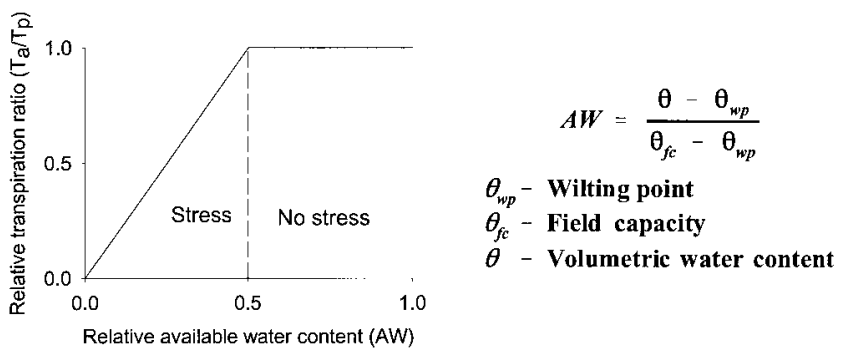

Fig. 1. Relationship between available water and the relative transpiration ratio.

zero until $5 \mathrm{~d}$ after planting, and (v) the rates of change of a) vertical root growth and b) $Z_{1 / 2}$ with time are both zero at the time of $75 \%$ silking. These given conditions provide six known values of the variables that allow us to solve for the six coefficients $\left(\beta_{1}-\beta_{6}\right)$ in Eqs. [4] and [5]. The conditions given in 1 to 5 above were developed from data given in NaNagara et al. (1976)

In SD-SPM, water from precipitation is added to the soil profile as piston flow displacement. Actual transpiration $\left(\mathrm{T}_{\mathrm{a}}\right)$ and potential transpiration $\left(\mathrm{T}_{\mathrm{p}}\right)$ are estimated by a water budgeting procedure based on precipitation, pan evaporation, crop growth stage, root growth, and the water holding capacity of the soil within the rooting zone. The ratio of actual to potential transpiration $\left(\mathrm{T}_{\mathrm{a}} / \mathrm{T}_{\mathrm{p}}\right)$ is estimated as a function of the available water in the rooting zone (Fig. 1). Available water is a function of climate and the soil properties that determine water storage capacity. Water uptake from a particular layer depends on the relative root density in that layer (Selirio and Brown, 1979).

\section{Crop Yield Estimation}

Water stress is related to yield through a seasonal water stress index $\left(\mathrm{S}_{\mathrm{S}}\right)$ adapted from Hiler and Clark (1971) and defined as:

$$
S_{S}=\sum_{i=1}^{n}\left(S_{D i}\right)\left(W_{i}\right)
$$

where $n$ is the number of days from planting to harvest, and $W_{i}$ is a weighting factor that accounts for the sensitivity of grain yield to water stress on that day. The value for $W_{i}$ varies with respect to the growth stage. The duration of the growth stages are given in Table 1. The weighting factors have been determined from an analysis of irrigation experiments reported in the literature (Barret and Skogerboe, 1978; Stewert et al., 1975; Harder et al., 1982) and are given in Table 1. These have been simplified from the original weights given in Timlin et al. (1986). In the original work, the weighting factor was adjusted for stress in previous periods. This modification was dropped since it only had a small effect on predicted yields and made the model too sensitive to the distribution of growth stages. $S_{D i}$ is the daily stress index for Day $i$ as calculated from:

$$
\mathrm{S}_{\mathrm{D}}=1-\mathrm{T}_{\mathrm{a}} / \mathrm{T}_{\mathrm{p}}
$$

and $T_{a} / T_{p}$ is the relative transpiration ratio.

Hiler and Clark (1971) and Shaw (1974) used this stress index to calculate corn grain yield as:

$$
\mathrm{YIELD}=\mathrm{Y}_{\mathrm{P}}-(\mathrm{A})\left(\mathrm{S}_{\mathrm{S}}\right)
$$

where $Y_{P}$ is potential yield when water is not limiting and $A$ is the change in corn grain yields in $\mathrm{Mg} \mathrm{ha}^{-1}$ per unit of seasonal water stress (water stress response coefficient). The water stress response coefficient $(A)$ and potential yield $\left(Y_{P}\right)$ 
in Eq. [7] were estimated for each year of the Aurora data by regressing yields measured at sites with different rooting depths against the calculated stress index. The intercept at zero stress index was taken as the potential yield $\left(Y_{P}\right)$, and the slope of the line was taken as the water stress response coefficient $(A)$.

In order to be able to represent results from different sites on a more general basis, we will redefine Eq. [2] as a relative yield equation by dividing Eq. [7] by potential yield $\left(Y_{P}\right)$. The result is:

$$
\mathrm{Y}_{\mathrm{R}}=1-\left(\mathrm{A}_{\mathrm{R}}\right)\left(\mathrm{S}_{\mathrm{S}}\right)
$$

where $Y_{R}=Y / Y_{P}$, and $A_{R}=A / Y_{P}$ is the relative water stress response coefficient. An estimate of potential yield $\left(Y_{p}\right)$ was obtained from experimental data by regressing measured yields on seasonal water stress indices $\left(S_{S}\right)$ obtained from the water budget.

Relative yields and a relative stress index were also calculated for the Canton data which were originally used to test the water stress component of the model (Timlin et al., 1986). The authors tested the water stress component by using half the Canton data ( $8 \mathrm{yr})$ to calibrate the model and the other half to test the predictions. The equation fit to all the data was:

$$
\text { YIELD }=[7.51(\mathrm{OCHU})-4441]-198\left(\mathrm{~S}_{\mathrm{s}}\right) \text { [9] }
$$

Where yield was in $\mathrm{kg} \mathrm{ha}^{-1}$ and OCHU are Ontario Corn Heat Units (Daynard, 1972). Note that in this equation, $Y_{p}$ from Eq. [7] was calculated as a function of Ontario Corn Heat Units (7.51 OCHU-4441) and the water stress-response coefficient, $A$ from Eq. [7] is $198 \mathrm{~kg} \mathrm{ha}^{-1}$. A calibration equation developed from half the data predicted the validation grain yields well.

Potential yield calculation was separated from the water stress component in order to calculate a relative water stress response coefficient ( $A_{R}$ in Eq. [8]) for the Canton Data. Since the rooting depth of the soil at this site was relatively deep $(>0.90 \mathrm{~m})$, the variation in potential yield from year to year was assumed to be a function of temperature alone and potential yield was estimated from Ontario Corn Heat Units (OCHU). In New York state, temperature and precipitation are major sources of variation in corn grain yields (Russo, 1978). Estimates of potential yields $\left(Y_{p}\right)$ for 16 years of data were obtained by regressing measured yields on OCHU only (setting $\mathrm{S}_{\mathrm{S}}$ to zero). A relative water stress response coefficient for the Canton data was obtained by regressing relative yields $\left(\mathrm{Y} / \mathrm{Y}_{\mathrm{p}}\right)$ on calculated water stress indices.
Potential yield $\left(\mathrm{Y}_{\mathrm{p}}\right)$ was obtained by three methods for the Canton and Aurora data sets. These included mean irrigated yield (Aurora), OCHU in Eq. [9] (Canton), and by regressing yields measured over a range in soil depths on calculated seasonal stress indices (Aurora). The use of mean irrigated yield provides an estimate of potential yield that is independent of the data used to calculated stress indices and independent of the reduction in yield due to water stress, slope $A$ in Eq. [8]. Potential yield calculated from OCHU can be shown to be statistically independent of the reduction of yield due to water stress.

We recognize that there may be other sources of limiting factors for crop yields and it may not be possible to completely eliminate water stress. The proposed relationship, however should be able to quantify relative differences in yields when the main source of yield variability is due to water stress.

\section{Statistical Analysis}

Correlations, regressions, and Students $t$-tests were carried out using SAS statistical software (SAS Institute, 1995). Analysis of the irrigation treatment effects was done by testing the significance of the relationship between the increase in grain yield due to irrigation and soil depth. The increase in yield due to irrigation was regressed on soil depth and the significance of the relationship was tested by comparing the slope to 0 . The water stress response coefficients for the relative yield equations at the different sites and years were compared using Proc Reg of SAS (SAS Institute, 1995). We used indicator variables (Neter and Wasserman, 1974, p. 279-338) in multiple linear regression to obtain parameters for all relative yield equations to calculate values of the Students $t$-statistic to make comparisons.

\section{RESULTS AND DISCUSSION}

The results and discussion section will first discuss the irrigation results. The grain yield-soil depth relationships under normal rainfall will be discussed next and the final section will cover the application of the SDSPM.

\section{Weather}

The weather conditions over the three year period varied from very wet and cool to dry and warm (Fig.

\section{- - - CLASS A PAN EVAPORATION PRECIPITATION}
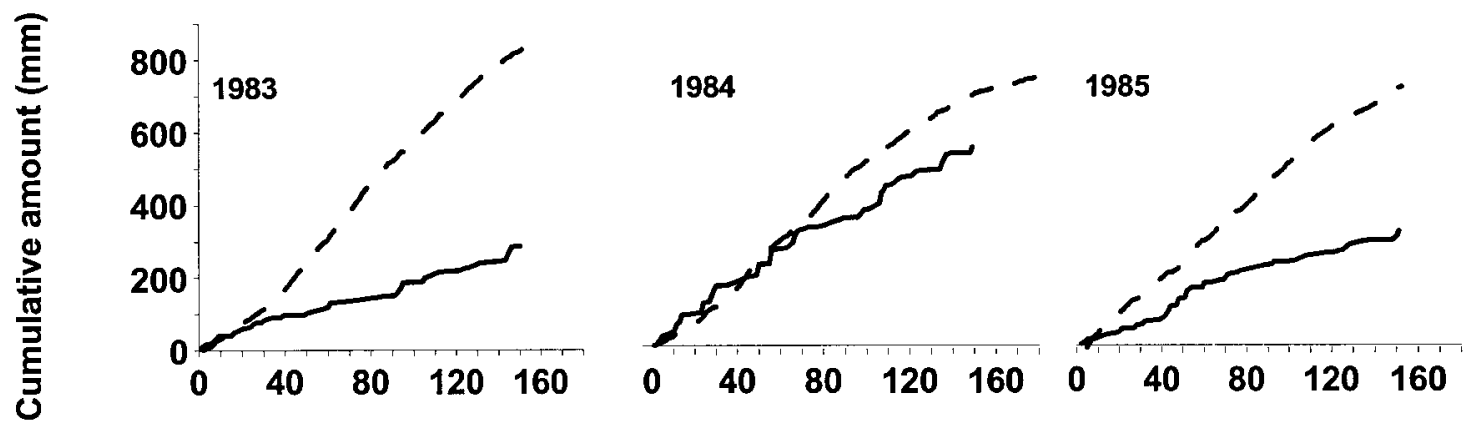

Days after May 1

Fig. 2. Cumulative rainfall and Class A pan evaporation at Aurora, NY (1983 to 1985). 


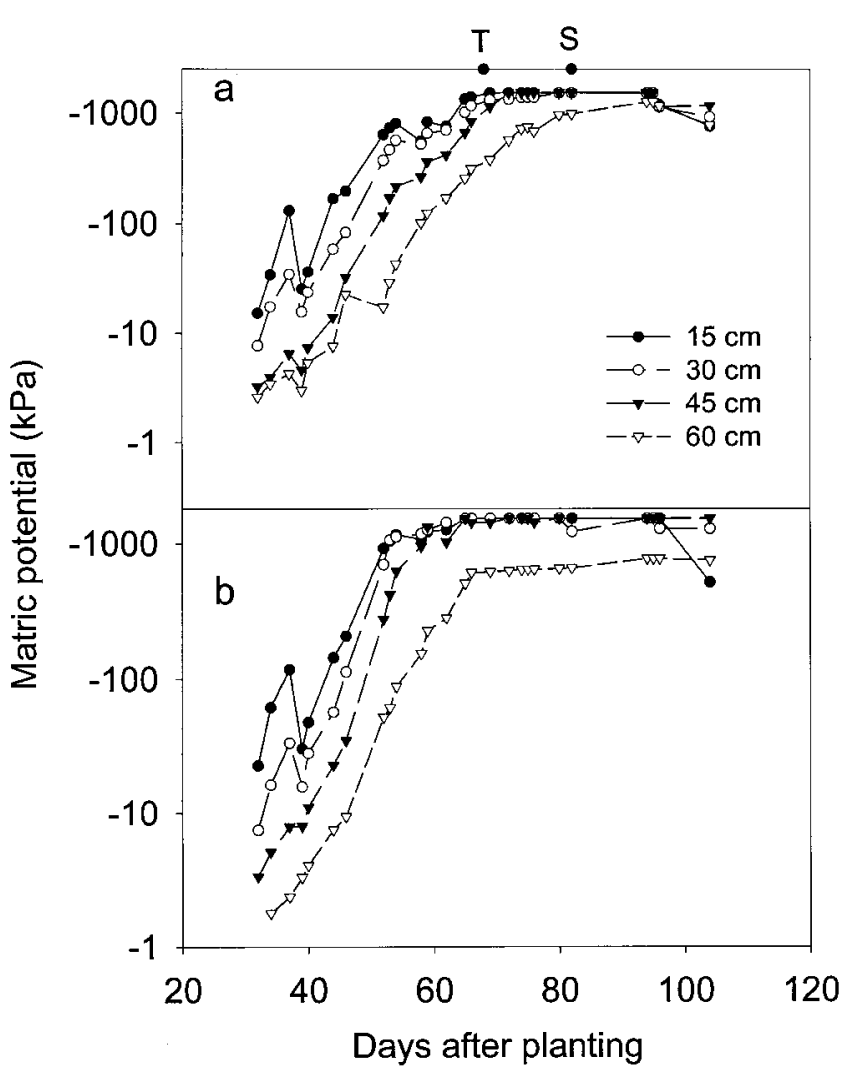

Fig. 3. Mean water potential data for the 1985 nonirrigated plots from tensiometers and gypsum blocks; (a) water potentials for plots where soil rooting depth $>0.50 \mathrm{~m}$ and (b) water potentials for plots with soil rooting depth $<0.50 \mathrm{~m}$. The symbols $T$ and $S$ indicate timing of $50 \%$ tasseling and silking respectively. The calibrated range of the gypsum blocks did not extend to matric potentials more negative than $-1500 \mathrm{kPa}$.

2). The summers were warm and dry in 1983 and 1985. In contrast, the summer of 1984 was cool and wet. The water potential data (Fig. 3) reflect the dry conditions for 1985 . The soil in the shallow root zone $(<0.5 \mathrm{~m})$ reached lower matric potentials than the soil with the deeper root zone and remained at these lower potentials for a long period of time.

\section{Comparisons of Irrigated and Nonirrigated Grain Yields Under Variable Rooting Depth}

The grain yield increased with increasing soil depth in the non irrigated plots and irrigation increased grain yield in all plots (Fig. 4). The mean irrigated yield was $6.82 \mathrm{Mg} \mathrm{ha}^{-1}$ with a standard deviation of $0.504 \mathrm{Mg} \mathrm{ha}^{-1}$ while the mean non irrigated yield was $3.446 \mathrm{Mg} \mathrm{ha}^{-1}$ with a standard deviation of $1.419 \mathrm{Mg} \mathrm{ha}^{-1}$. The mean yield difference between irrigated and nonirrigated plots was $3.375 \mathrm{Mg} \mathrm{ha}^{-1}$. The irrigated yields did not significantly change with soil depth and all the values are contained in a $95 \%$ confidence interval around the mean irrigated yield.

The slope $\left(-9.27 \mathrm{Mg} \mathrm{ha}^{-1} \mathrm{~m}^{-1}\right.$ soil depth) for the relationship between change in yield due to irrigation and soil depth (Fig. 5) was significant $(t=-5.83, P<$ 0.001 ); increases due to irrigation were much greater on the shallow plots $(<0.50 \mathrm{~m})$ than on the deeper ones.

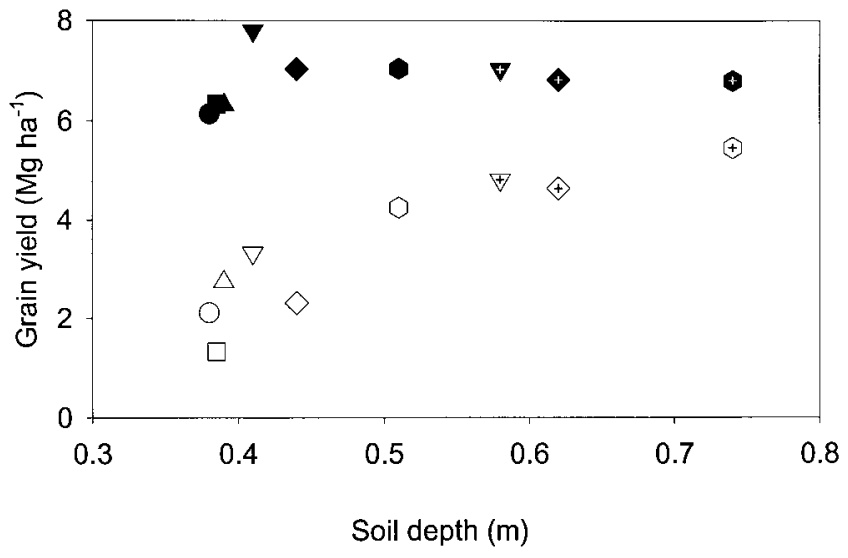

Fig. 4. Comparison of irrigated and nonirrigated corn grain yields as a function of soil depth at Aurora. The same shape symbols are shown for the paired irrigated and nonirrigated plots. Filled symbols denote irrigated plots and hollow symbols nonirrigated.

The water potential data in Fig. 3 show that the deeper plots still had more available water below $0.45 \mathrm{~m}$ than the shallow plots between the times of tasseling and silking (indicated by $\mathrm{T}$ and $\mathrm{S}$ ).

\section{Relationships Between Measured Grain Yield and Soil Depth for Nonirrigated Conditions}

Soil depth-yield trends were clear during 1983 and 1985 (Fig. 6). During the 1984 growing season, greater than average rainfall and cool conditions probably resulted in increased yield variability. On the basis of visual observations, we believe that the effects of poor aeration (water logging) probably dominated at many locations. The water potential data measured in the non irrigated plots (Fig. 3) and the irrigation results suggest that the soil depth-yield relationships in 1983 and 1985 were strongly related to water availability. Judging by the narrow range of variability in the irrigated plots, we hypothesize that water availability was the major source of variability at this site for the dry years 1983, and 1985.

\section{Modeling the Relationship Between Rooting Depth and Crop Yield}

Measured soil depth and grain yields described in the previous section were used to evaluate the SD-SPM over a range of soil depths. Based on measured precipitation and evaporation data given as input, along with

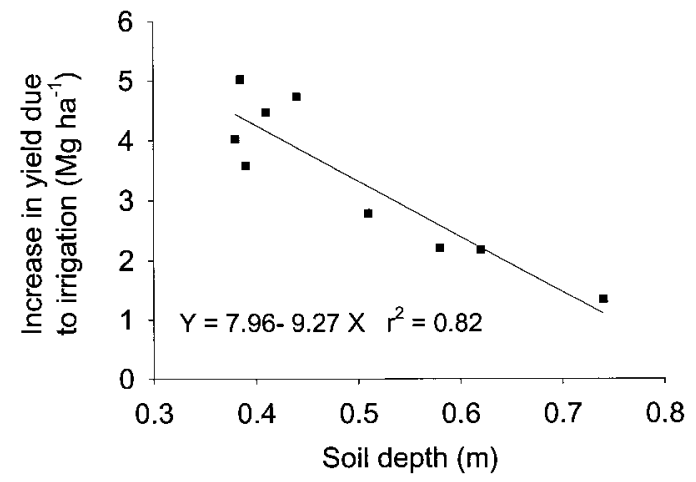

Fig. 5. Response to irrigation vs. soil depth. 


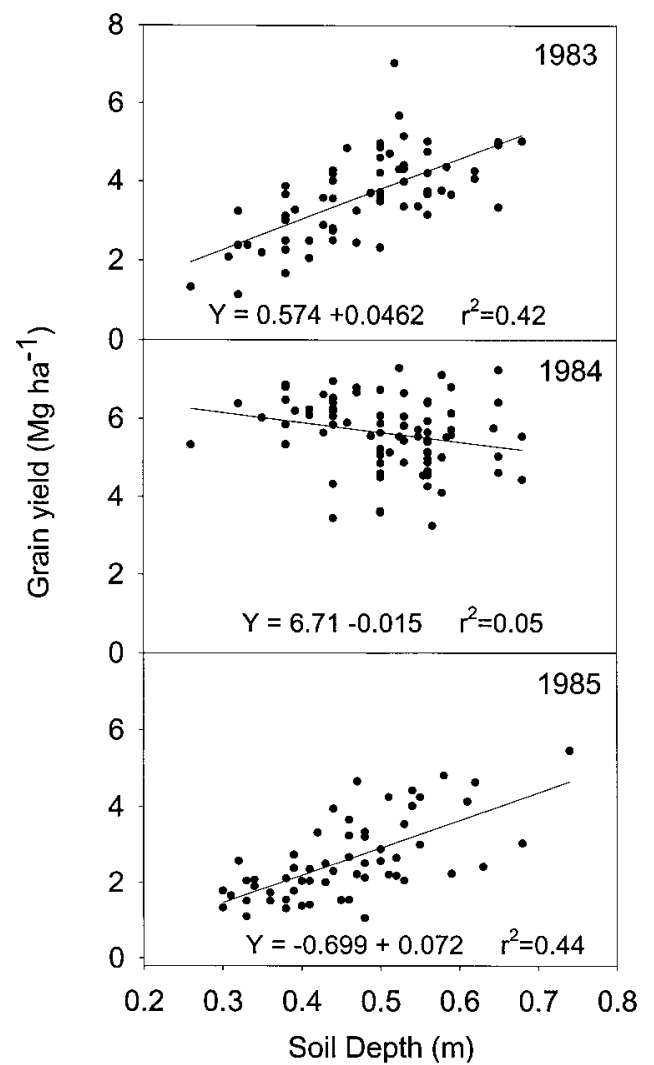

Fig. 6. Corn grain yield vs. soil depth at Aurora, 1983-1985.

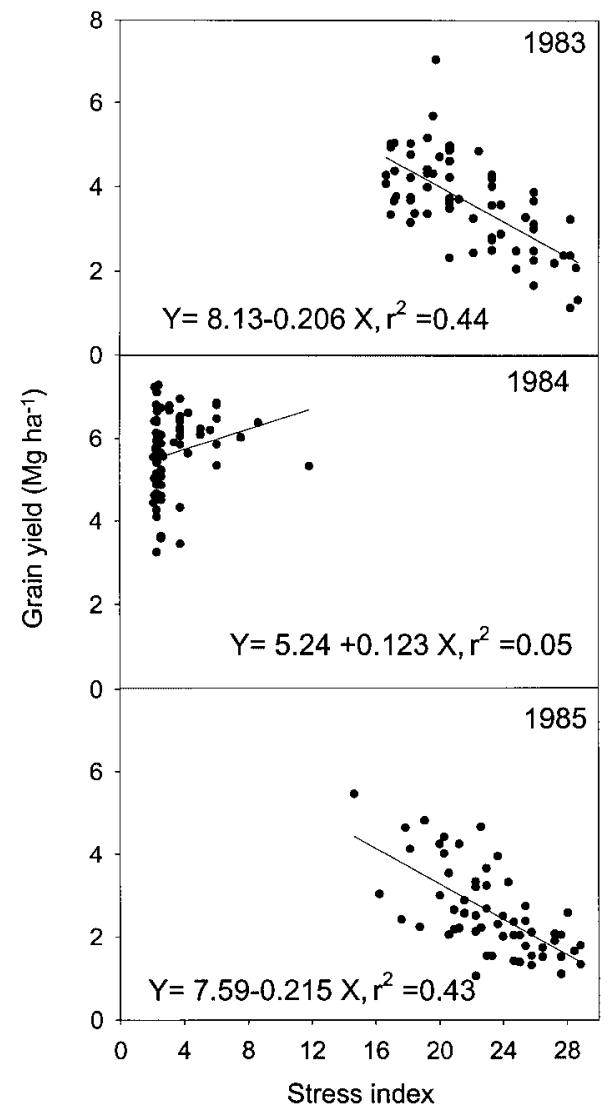

Fig. 7. Grain yield vs. calculated stress index for Aurora, 1983-1985. crop (crop growth stage and maximum potential rooting depth) and soil data (water holding capacity), the water budget component of the SD-SPM calculated values for actual and potential transpiration that were used in Eq. [7] to calculate a seasonal stress index $\left(S_{S}\right)$. The seasonal stress indices for the Aurora data shown in Fig. 7 appear to vary linearly with measured yield. Since 1984 was a wet year with little water stress, the 1984 data will not be considered further in this analysis.

Mean irrigated yield also was an independent estimate of potential yield $(Y p)$ which was defined as grain yield when water was not limiting. Estimated potential yield for 1985 compared favorably with mean irrigated yield. The confidence interval ( $95 \%$ ) for potential yields in 1985 by the standard error of the intercept for Eq. [7] (Table 2) is $7.59 \pm 1.5 \mathrm{Mg} \mathrm{ha}^{-1}$. The corresponding mean irrigated yield is $6.8 \mathrm{Mg} \mathrm{ha}^{-1}$. The general agreement of measured potential yield with predicted potential yield suggests that the stress index realistically estimates the change in grain yield per unit water stress.

The correlations between stress index and grain yield were strong when water stress was most severe as in 1983 and 1985. Saxton and Bluhm (1982) by a similar stress index also reported higher correlation coefficients for sites characterized by severe water stress. Soil depth has been shown to be a better predictor of soybean (Glycine max L.) yield at sites with low organic matter, especially when rainfall also was low (Hairston et al., 1988). At low values of stress index, sources of variation other than water become important in determining yield variation (Shaw and Felch, 1972). The calculated stress indices for 1984 were much lower than for 1983 or 1985 (Fig. 7, 1984) because there was more rainfall in 1984. Many of the areas characterized by deep soil profiles occurred in slight depressions. Our interpretation is that, during the wet year of 1984, the more shallow soils tended to have better drainage and accumulate less water than the areas with deeper soil profiles. As a result, the crop on the more shallow soils did not suffer as much from poor drainage and had relatively higher yields. Since water was not limiting in 1984, however, we did not expect to see a significant relationship between soil depth and grain yield.

Other sources of variability were most likely factors associated with lack of uniformity in management. Weeds were difficult to control and had varying effects on yield. However, in the irrigated and non irrigated plots, weeds were controlled by hand weeding. Plant populations and fertilizer applications appeared to be somewhat variable.

Table 2. Potential yields and water stress response coefficients from grain yield-stress index relationships at Aurora and Canton, NY.

\begin{tabular}{|c|c|c|c|c|c|c|c|c|}
\hline Site & Year & $\mathbf{Y}_{\mathbf{P}}$ & $\mathbf{A}$ & $S_{A} \neq$ & $r^{2}$ & $\mathbf{t}_{\mathrm{A}} \S$ & $\mathbf{A}_{\mathrm{R}}$ & $\mathbf{S}_{\mathrm{AR}}$ \\
\hline & \multicolumn{8}{|c|}{$-\mathbf{M g ~ h a}^{-1}$} \\
\hline Aurora & 1983 & 8.10 & -0.206 & 0.003 & 0.441 & $\mathbf{7 . 2 0}$ *** & -0.025 & 0.003 \\
\hline Aurora & 1985 & 7.59 & -0.215 & $\mathbf{0 . 0 3 3}$ & 0.433 & $6.54 * * *$ & -0.028 & 0.004 \\
\hline Canton & (16 yrs) & $\mathbf{N} / \mathbf{A} \dagger$ & -0.198 & 0.037 & 0.650 & $5.34 * * *$ & -0.029 & 0.005 \\
\hline
\end{tabular}


Nevertheless, in spite of these sources of variation, the calculated stress indices do follow the trends of the data.

\section{Relationships Between Relative Yields and Relative Stress Indexes}

When Eq. [7] was converted to the relative yield basis (Eq. [8]) for the Aurora data by dividing measured yields by the calculated $Y_{P}$ values (Table 2) and regressing on the stress indices, the resulting relative water stress response coefficients, $A_{R}$, were similar for both 1983 and 1985 (Table 2).

A relative water stress response coefficient was also calculated for the Canton data. Potential yields were calculated from the OCHU by setting the seasonal stress index $\left(S_{S}\right)$ to zero (Eq. [9]). There was no significant interaction at this site between the transpiration ratio and temperature (as determined by regressing yield on both calculated stress index and temperature and comparing the coefficients with those obtained from single variable regressions). The relative stress index was 0.029 and was similar to those calculated for Aurora (Table 2).

The relative grain yield vs calculated seasonal stress index for the 1983 and 1985 Aurora data, and the Canton data were linear and the three data sets appear to conform to the same relationship (Fig. 8). The relative stress response coefficients were not significantly different from each other. The $F$ values to test the differences between slopes were close to 0 for all the comparisons. Therefore the three data sets were combined and one regression equation fit to them. The fitted equation is:

$$
\mathrm{Y}_{\mathrm{R}}=1.01-0.027 \times \mathrm{S}_{\mathrm{S}}\left(\mathrm{r}^{2}=0.79\right)
$$

where $A_{R}$ is 0.027 .

It is noted that the intercept is not significantly different from 1. By making this approximation, Eq. [10] can be made similar to Eq. [8]. The relative yield equation is then:

$$
\mathrm{Y}_{\mathrm{R}}=1-0.027 \times \mathrm{S}_{\mathrm{S}}
$$

The fitted equation describes the relative yield-seasonal water stress index data well (Fig. 8).

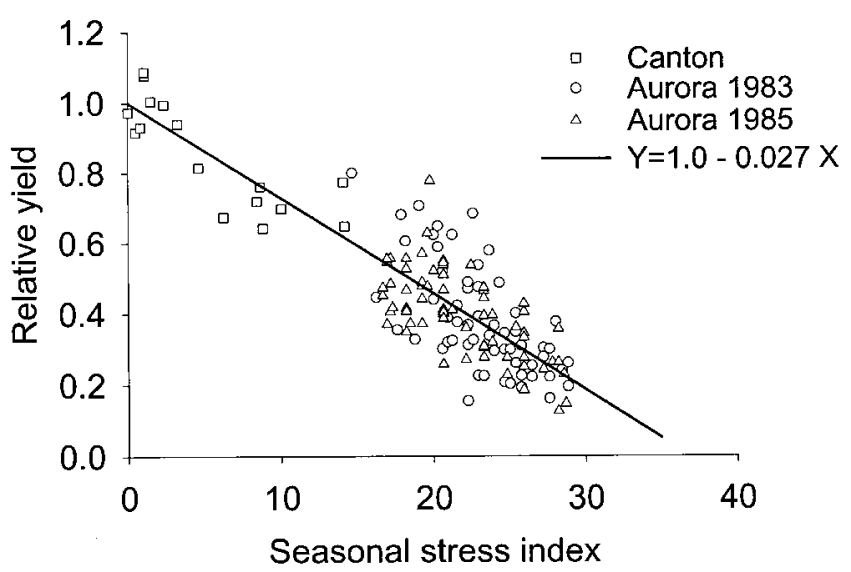

Fig. 8. Relative yield vs. calculated stress index for Canton, 1983 and 1985 Aurora data.

\section{Comparison of Measured and Estimated Relative Yields Over a Range of Soil Depths}

Independent estimates of relative yields for 1985 were calculated by dividing measured yields by mean irrigated yield. This gave an estimate of relative yield that was independent of the regression with stress indices. In order to have an estimate of the relative stress index that was independent of the 1985 data for comparative purposes, the slope in Eq. [8] was taken to be 0.029, that calculated from the Canton data. The comparison, shown in Fig. 9 demonstrate that the model reasonably predicts the average changes in relative yield as rooting depth varies. The mean square error was 0.017 in units of relative yield.

Where soil depth was greater than approximately 0.55 $\mathrm{m}$, many of the relative grain yield values were greater than the predicted values (as indicated by the line in Fig. 9 ). This indicates that the model overestimates moisture stress for deeper soil depths. There could be a number of reasons for this. Since the relative stress response coefficient, $A_{R}$, from the Canton data was used to predict the Aurora data there could be site differences in this coefficient. Site effects can be minimized however by having a coefficient developed using data from a number of sites. It is also possible that the available soil water content where the relative transpiration rate becomes less than one (Fig. 1), is different from 0.5 or the relationship is non linear. Errors in soil depth measurement could also contribute to such differences. The model predicts relative yields well, however for this site.

\section{SUMMARY AND CONCLUSIONS}

Results of the irrigation experiments provided evidence that water availability was a major cause of yield variability when the weather was very dry. During the wet year of 1984, yields were affected by excess water and the magnitudes of the stress indices calculated for that year were much smaller than for 1983 or 1985. Clearly observable water stress-yield relationships occurred when water stress was relatively severe as in 1983 and 1985.

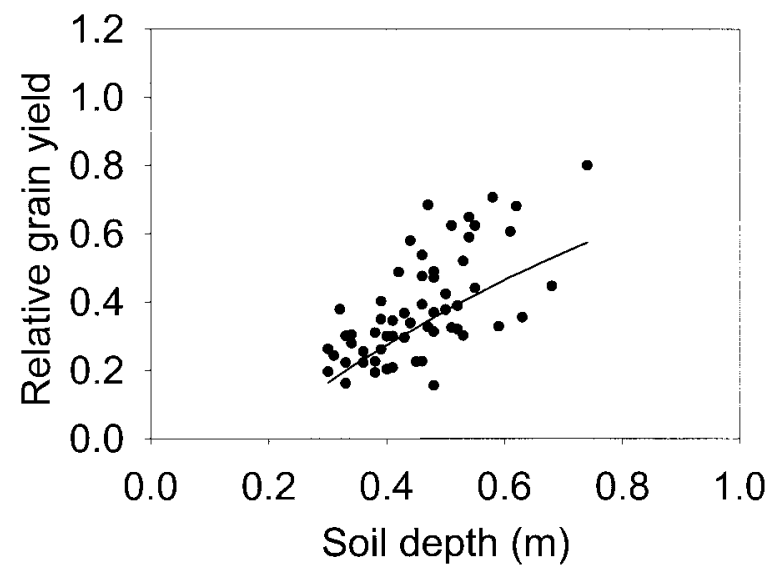

Fig. 9. Measured relative grain yields and relative yield predicted by Eq. [8] vs. soil depth for the 1985 data. 
Where soil depth-yield relationships existed, the measured data followed the same trend as the predicted relationships. One relative yield equation was found to predict all trends with reasonable accuracy. The equation was:

$$
\mathrm{Y}_{\mathrm{R}}=1-0.027 \times \mathrm{S}_{\mathrm{S}}
$$

The objective of this research was to show that the major source of variability in corn grain yields could be related to water holding capacity, a function of soil depth. Furthermore, a simple water budget model could be used to quantify this variability. Many factors other than water were probably involved in the yield variability. However, observed trends of yield with soil depth were predicted reasonably well by the model on the basis of water relations, and the irrigation experiments verified this. The water stress response coefficient for the water stress index to predict relative yield was shown to only vary slightly for three data sets from New York using a short season variety of corn. The generality of this expression needs to be investigated over a wider range of data. An independent test of the model where potential yield was obtained from irrigation experiments and the relative stress index component from the Canton data, showed that the model predicted relative yields for the 1985 Aurora data reasonably well (mean square error of 0.017 ). The predicted values were closest to measured, where the soil depth was less than $0.60 \mathrm{~m}$. The model tended to underpredict relative yield where soil depth was greater than $0.60 \mathrm{~m}$.

The simple water budget and relative yield model as described here can be used as a tool to evaluate potential productivity in a landscape as a function of available water and weather. The model can be used to quantify the effects of weather on corn yield.

\section{ACKNOWLEDGMENTS}

The authors gratefully acknowledge the assistance of Dr. Jeff Wagenet for his guidance in this study, the anonymous reviewers, and Dr. Rob Aiken for their many helpful suggestions.

\section{REFERENCES}

Barnhisel, R.I., M.J. Bitzer, J.H. Grove, and S.A. Shearer. 1996. Agronomic benefits of varying corn seed populations: a central Kentucky study. p. 957-965. In P.C. Robert et al. (ed.) Precision agriculture. Proc. Int. Conf., 3rd, 23-26 June 1996, Minneapolis, MN.

Barrett, J.W.H, and G.V. Skogerboe. 1978. Effect of irrigation regime on maize yields. J. Irrig. Drain. Div. Am. Soc. Civ. Eng. 104:179-194.

Boyer, D.G., R.J. Wright, W.M. Winant, and H.D. Perry. 1990. Soil water relations on a hilltop cornfield in central Appalachia. Soil Sci. 149:383-392.

Cahn, M.D., J.W. Hummel, and B.H. Brouer. 1994. Spatial analysis of soil fertility for site specific crop management. Soil Sci. Soc. Am. J. 58:1240-1248.

Davidson, J.M., D.A. Graetz, P.S.C. Rao, and H.M. Selim. 1978. Simulation of nitrogen movement, transformation and uptake in the plant root zone. Ecological Res. Series no. 29, EPA-600/3-7829. U.S. Govt. Printing Office, Washington, DC.

Daynard, T.B. 1972. Relationships among blacklayer formation, grain moisture percentage, and heat unit accumulation in corn. Agron. J. 64:716-719.
Fehrenbacher, J.B., and R. Rust. 1956. Corn root penetration in soils derived from various textures of Wisconsinan-age till. Soil Sci. 82: 369-378.

Frye, W.W., C.W. Murdock, and R.L. Blevins. 1983. Corn yield-depth relationships on a Zanesville Soil. Soil Sci. Soc. Am. J. 47:1043-1045.

Gantzer, C.J., and T.R. McCarty. 1987. Predicting corn yields on a claypan soil: A soil productivity index. Trans. ASAE 30:1347-1352.

Hairston, J.E., J.O. Sanford, F.E. Rhoton, and J.G. Miller. 1988. Effect of soil depth and erosion on yield in the Mississippi Blacklands. Soil Sci. Soc. Am. J. 52:1458-1463.

Hanks, R.J. 1974. Model for predicting plant yield as influenced by water use. Agron. J. 66:660-665.

Harder, H.J., R.E. Carlson, and R.H. Shaw. 1982. Yield, yield components, and nutrient content of corn grain as influenced by post silking moisture stress. Agron. J. 74:275-278.

Hiler, E.A., and R.N. Clark. 1971. Stress day index to characterize effects of water stress on crop yields. Trans. ASAE 14:757-761.

Khakural BR, P.C. Robert, and A.M. Starfield. 1996. Predicting corn yield across a soil landscape in west central Minnesota using a soil productivity model. p. 197-206. In P.C. Robert et al. (ed.) Precision agriculture. Proc. Int. Conf., 3rd, 23-26 June 1996, Minneapolis, MN.

Marthaler, H.P., W. Vogelsanger, F. Richard, and P.J. Wierenga. 1983. A pressure transducer for field tensiometers. Soil Sci. Soc. Am. J. 47:624-627.

Matthews, R.B., and N.D. Cosser. 1997. Using crop simulation models to develop treatment maps in precision agriculture. p. 181-190. In M.J. Gooding and P.R. Shewry (ed.) Optimizing cereal inputs: its scientific basis. Part 1: Genetics and nutrition, Cirencester, UK, 15-17 December 1997. Aspects-of-Applied-Biology. 1997, No. 50.

Mengel, D.B., and S.A. Barber. 1974. Development and distribution of the corn root system under field conditions. Agron. J. 66:341-344.

Moore, G.A., and J.P. Tyndale-Biscoe. 1999. Estimation of the importance of spatially variable nitrogen application and soil moisture holding capacity to wheat production. Prec. Agric. 1:27-38.

Neter, J., and W. Wasserman. 1974. Applied linear statistical models Richard D. Irwin, Inc., Homewood, IL.

Olson, K.R. 1983. Soils and climate effects on yields for assessment evaluations. Ph.D. diss. Cornell University, Ithaca, NY (Diss. Abstr. 44:1679B)

Paz, J.O., W.D. Batchelor, T.S. Colvin, S.D. Logsdon, T.C. Kaspar, and D.L. Karlen. 1998. Analysis of water stress effects causing spatial yield variability in soybeans. Trans. ASAE 41:1527-1534.

Retta, A., and R.J. Hanks. 1981. Manual for using model PLANTGRO. Utah Agric. Exp. Stn. Res. Pub. 48.

Russo, J.M. 1978. A method for evaluating the crop system: an application to corn. Ph.D. diss. Cornell University, Ithaca, NY (Diss. Abstr. 39:3090B.)

SAS Institute. 1995. SAS/STAT guide for personal computers. Version 6.07 ed. SAS Inst., Cary, NC.

Saxton, K.E., and G.C. Bluhm. 1982. Regional prediction of crop water stress by soil water budgets and climatic demand. Trans. ASAE 25:105-115.

Selirio, I.S., and D.M. Brown. 1979. Soil moisture based simulation of forage yield. Agric. Meteorol. 20:99-114.

Shaw, R.H., and R.E. Felch. 1972. Climatology of a moisture stress index for Iowa and its relationship to corn yields. Iowa State J. Sci. 46:357-368.

Shaw, R.H. 1974. A weighted moisture-stress index for corn in Iowa. Iowa State J. Sci. 49:101- 114.

Stewert, J.I., R.D. Misra, W.D. Pruitt, and R.M. Hagan. 1975. Irrigating corn and grain sorghum with a deficient water supply. Trans. ASAE 18:270-280.

Swan, J.B., M.J. Shaffer, W.H. Paulson, and A.E. Peterson. 1987. Simulating the effects of soil depth and climatic factors on corn yield. Soil Sci. Soc. Am. J. 51:1025-1032

Thompson, A.L., C.J. Gantzer, and S.H. Anderson. 1991. Topsoil depth, fertility, water management, and weather influences on yield. Soil Sci. Soc. Am. J. 55:1085-1091.

Timlin, D.J., R.B. Bryant, V.A. Snyder, and R.J. Wagenet. 1986. Modeling corn grain yields in relation to soil erosion using a water budget approach. Soil Sci. Soc. Am. J. 50:718-723. 